\title{
A STUDY ON CLINICAL PROFILE OF ECTOPIC THYROID GLAND FROM A TERTIARY CARE HOSPITAL
}

\author{
K. Neelaveni1, A. Datta Reddy², Rakesh Kumar Sahay ${ }^{3}$ \\ ${ }^{1}$ Associate Professor, Department of Endocrinology, Osmania Medical College, Osmania General Hospital, Hyderabad. \\ ${ }^{2}$ Senior Resident, Department of Endocrinology, Osmania Medical College, Osmania General Hospital, Hyderabad. \\ 3 Professor and HOD, Department of Endocrinology, Osmania Medical College, Osmania General Hospital, Hyderabad.
}

\section{ABSTRACT}

\section{BACKGROUND}

Ectopic thyroid tissue is a rare developmental abnormality due to aberrant embryogenesis of the thyroid gland during its descent from the floor of the primitive foregut to its final position in the neck.

Objective is to study the clinical characteristics of patients with ectopic thyroid gland.

\section{MATERIALS AND METHODS}

In this case series study, we retrospectively reviewed the medical records of 21 patients with ectopic thyroid gland attending the endocrinology clinic of tertiary care teaching hospital between August 2011 and August 2016. Clinical presentation, thyroid status, nuclear imaging and management outcomes were analysed.

\section{RESULTS}

Mean age of presentation was 13.62 years (Range 3-37 years). Fifteen patients were female and six were male (Ratio 5:2). Fourteen patients $(66.67 \%)$ had lingual thyroid, whereas four patients $(19.02 \%)$ had thyroid gland at suprahyoid and two patients $(9.52 \%)$ had at subhyoid location. Only one patient had dual thyroid. Nineteen patients $(90.48 \%)$ had thyroid deficiency ( subclinical hypothyroidism in $38 \%$ or overt hypothyroidism in $52.38 \%$ ) and only two (9.52\%) were euthyroid. Seventeen patients (80.95\%) were treated medically, only two (9.52\%) patients underwent surgery. In twelve patients (57.14\%) ectopic thyroid gland was detected incidentally, whereas six patients $(28.57 \%)$ presented with neck swelling, two patients $(9.52 \%)$ with dysphagia and one patient (4.76\%) with dysphagia and respiratory difficulty.

\section{CONCLUSION}

Ectopic thyroid gland is rare, but important diagnosis to be considered especially in children with hypothyroidism. Clinical examination and nuclear imaging aid in correct diagnosis. Treatment should be individualised.

\section{KEYWORDS}

Ectopic, Eutopic Gland, Orthotopic Thyroid, Lingual Thyroid, Sublingual Thyroid, Subhyoid.

HOW TO CITE THIS ARTICLE: Neelaveni K, Reddy AD, Sahay RK. A study on clinical profile of ectopic thyroid gland from a tertiary care hospital. J. Evolution Med. Dent. Sci. 2016;5(82):6133-6136, DOI: 10.14260/jemds/2016/1385

\section{INTRODUCTION}

Ectopic Thyroid (ET) is a rare developmental abnormality, but one of the common form of thyroid dysgenesis. Ectopic thyroid refers to presence of functioning thyroid tissue in any location other than the normal pretracheal position. Mostly ectopic thyroid tissue is located in the midline along the line of descent, but occurrence in locations away from neck region, such as mediastinum and abdomen have been reported.(1,2,3,4) The most frequent location is the base of the tongue, where presence of ET may cause difficulty in swallowing and respiratory difficulty. Reported prevalence of ectopic thyroid is between 1 per $100000-300000$ persons, but the prevalence rises to 1 in 4000-8000 among patients with thyroid disease.(5) Postmortem studies(6) have reported that $7-10 \%$ of adults can have asymptomatic ectopic thyroid tissue located along the path of descent. To date approximately 550 cases of thyroid

Financial or Other, Competing Interest: None.

Submission 22-09-2016, Peer Review 04-10-2016,

Acceptance 06-10-2016, Published 13-10-2016.

Corresponding Author:

Dr. K. Neelaveni,

Associate Professor,

Department of Endocrinology,

Osmania Medical College, Hyderabad

E-mail: neelaveni1@yahoo.co.in

DOI: $10.14260 /$ jemds/2016/1385 ectopia have been reported in the literature. We describe the clinical presentation, location, thyroid functional status and management of patients with ectopic thyroid gland.

\section{MATERIALS AND METHODS}

We retrospectively analysed the medical records of patients diagnosed to have ectopic thyroid gland, who presented to the Endocrinology Clinic of a tertiary care teaching hospital between August 2011 and August 2016. Out of the total 24 patients only data of 21 patients analysed in the present study, as the data for the other three patients was incomplete. Clinical presentation, thyroid hormone profile, nuclear scan imaging of thyroid and the treatment modalities were analysed. Serum estimations of total T3, total T4 and thyrotropin (TSH) were done using chemiluminescence. Euthyroid status is defined as having TSH $<5 \mathrm{mIU} / \mathrm{L}$ with normal T4, subclinical hypothyroidism as having TSH $>5 \mathrm{mIU} / \mathrm{L}$ with normal T4 and overt hypothyroidism with TSH $>10 \mathrm{mIU} / \mathrm{L}$ and low T4. Nuclear imaging for thyroid was done using technetium Tc99m pertechnetate with gamma camera. Based on the clinical examination and nuclear imaging, location of the ectopic thyroid was classified as 1 . Lingual thyroid-situated at the base of the tongue, 2. Suprahyoid-situated between base of the tongue and hyoid, 3. Subhyoid-below the hyoid but above the orthotopic position of the thyroid gland. Dual ectopia is the presence of ectopic thyroid tissue with normally located 
thyroid as evident by imaging. Institutional Ethical Committee approval taken to analyse the data.

\section{RESULTS}

Out of total 21 patients, fifteen were female and six were male patients making the ratio of 5:2 (Fig. 1). Mean age of presentation was 13.62 years, age ranging between 3-37 years; $62 \%$ of the cases presented at less than 10 years of age as shown in Table 1. Fourteen patients $(66.67 \%)$ had lingual thyroid, whereas four patients $(19.02 \%)$ had thyroid gland at suprahyoid and two patients (9.52\%) had at subhyoid location. Only one patient had dual thyroid (Fig. 2). Nineteen patients (90.48\%) had thyroid deficiency (subclinical hypothyroidism in $38.1 \%$ and overt hypothyroidism in $52.38 \%$ ) and only two (9.52\%) were euthyroid (Fig. 3). Among hypothyroid patients seventeen patients (80.95\%) were treated medically, only two (9.52\%) patients underwent surgery. Euthyroid patients $(n=2)$ were also treated with suppressive doses of levothyroxine. In twelve patients (57.14\%) ectopic thyroid gland was detected incidentally who had lingual thyroid, whereas two patients (9.52\%) with dysphagia and one patient (4.76\%) with dysphagia and respiratory difficulty. Six patients $(28.57 \%)$ presented with neck swelling, who had either suprahyoid or subhyoid ectopic thyroid.
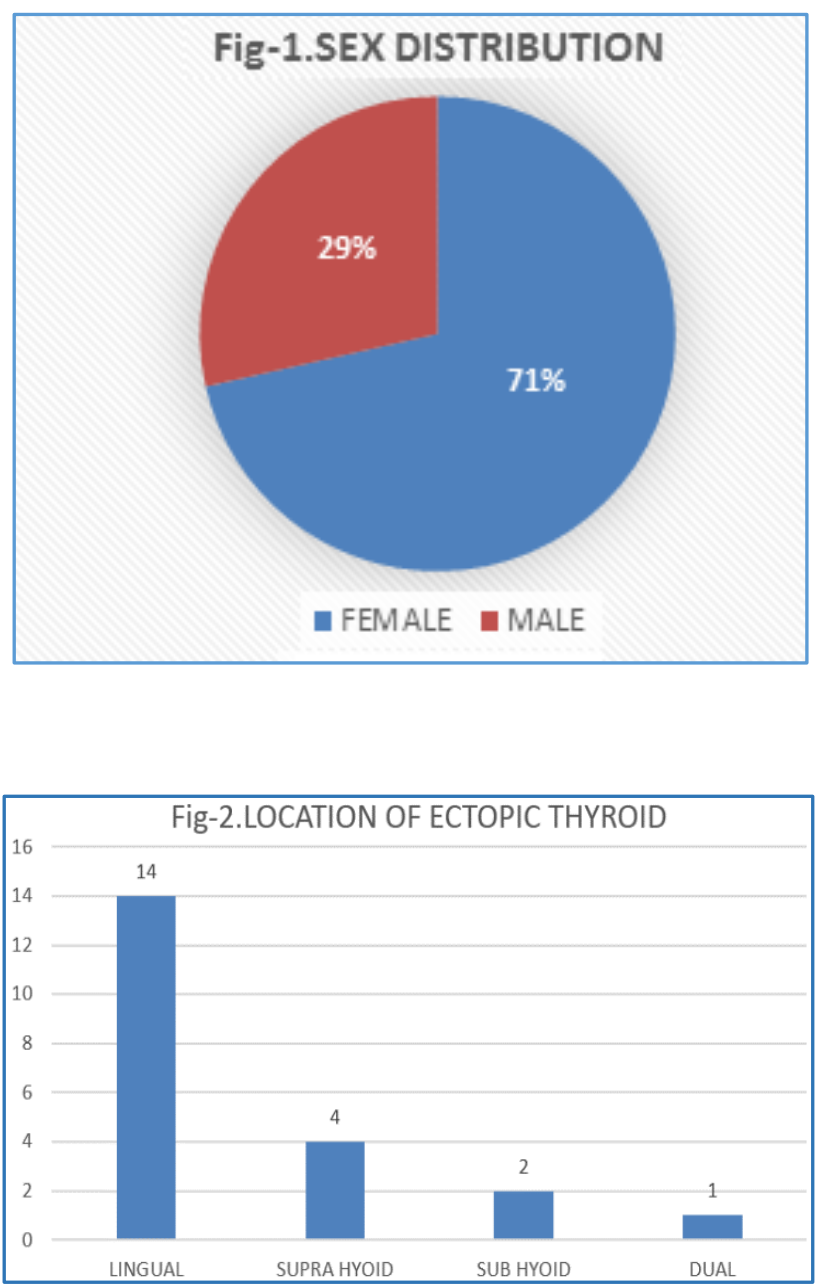
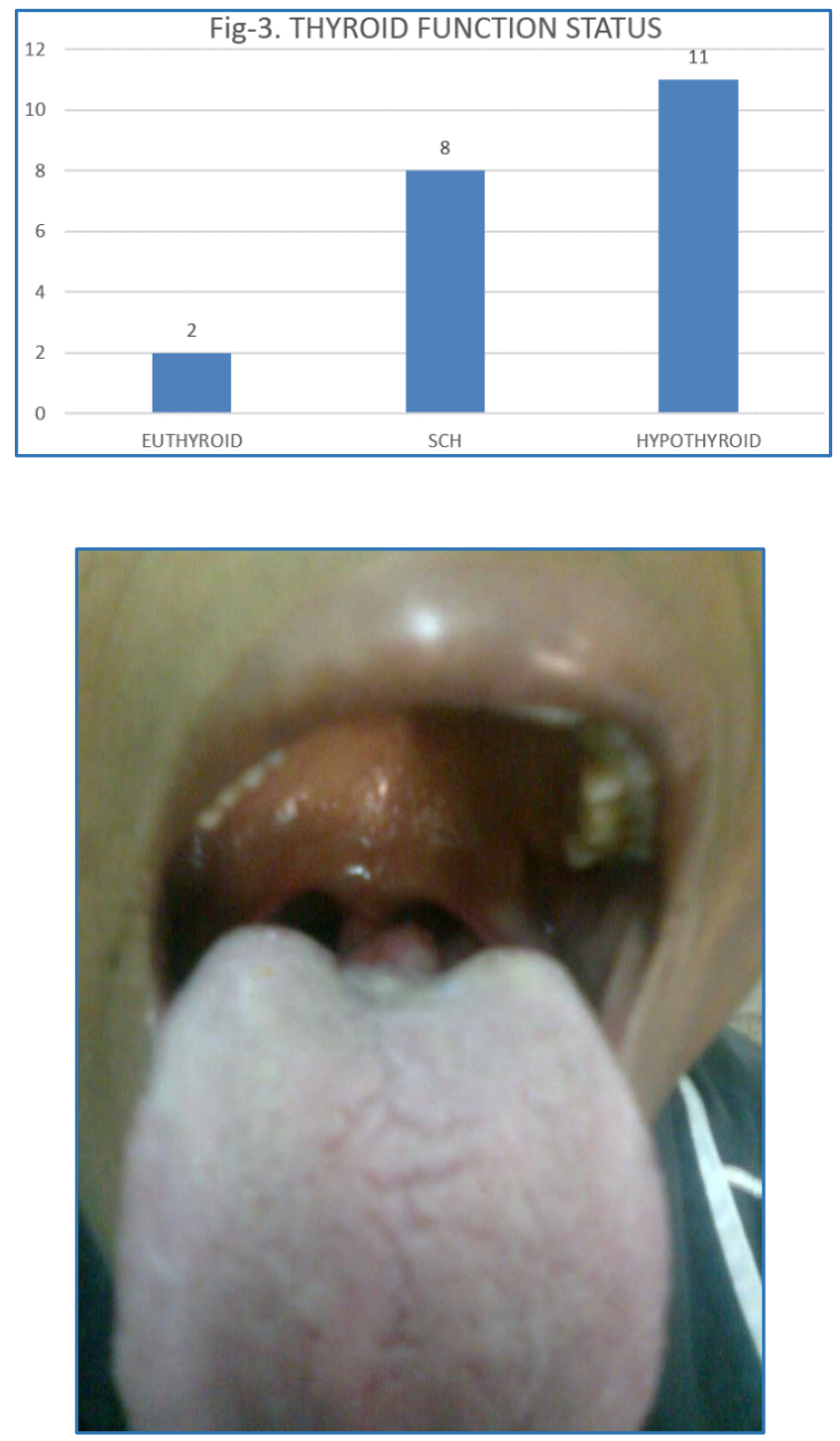

Fig. 4: Picture showing Lingual Thyroid

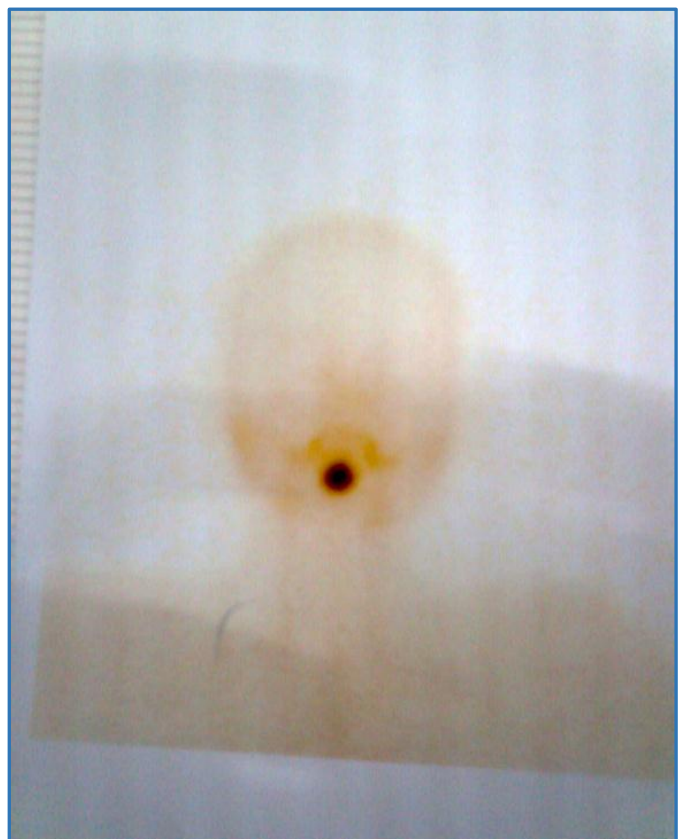

Fig. 5: Technetium 99

Pertechnetate Scan showing Lingual Thyroid 


\begin{tabular}{|c|c|c|}
\hline Age Group (In Years) & Frequency & Percent \\
\hline $0-10$ & 13 & 61.9 \\
\hline $11-20$ & 3 & 14.28 \\
\hline $21-30$ & 4 & 19.04 \\
\hline $31-40$ & 1 & 4.76 \\
\hline Total Table 1. Age Distribution \\
\hline \multicolumn{3}{|c|}{} \\
\hline
\end{tabular}

\section{DISCUSSION}

Ectopic thyroid is an uncommon clinical entity and its true prevalence may be underestimated due to asymptomatic nature of the condition. Thyroid gland during the process of migration remains connected to the floor of the pharyngeal gut, then it descends in front of hyoid bone to reach its pretracheal position in the $7^{\text {th }}$ week of gestation. ET may be found anywhere along the line of obliterated thyroglossal duct. The exact molecular mechanisms responsible are not clearly known, but studies have demonstrated the mutations of regulatory genes encoding for transcription factors - PAX-8, TTF-1 and TTF-2, which are essential for thyroid morphogenesis and differentiation may be responsible for abnormal migration of the gland. $(7,8)$

In all the case series and reviews on the ectopic thyroid reported so far, a marked female preponderance has been observed. $(5,9,10)$ In our series also we found female-to-male ratio of 5:2. Ectopic thyroid is commonly detected during the periods of increased demand for thyroid hormone, such as puberty and pregnancy. Because during this period ectopic gland increases in size, making it a clinically detectable mass or may cause pressure symptoms. Mean age of presentation in our series was 13.6 years, thirteen cases presented at the age below 10 years and seven cases between 11 and 30 years. Consistent with our observation, mean age of presentation in KEM Hospital study ${ }^{(9)}$ was 14.3 years. Age of presentation was under 30 years in case series by Somnath Saha et al(11) and Yoon et al.(5)

The most common location of ET is the base of the tongue in most case series. In earlier reports, this location accounted for $90 \%$ of cases.(12) Okstad et al(13) and Somnath Saha et al(11) found lingual thyroid, the most common followed by sublingual in their series. In contrast in KEM study, (9) authors found lingual thyroid in $47 \%$ of cases, whereas sublingual in $53 \%$ of the cases. In our series, most common location was lingual followed by sublingual. Dual ectopia was found in one case in our series, who had ectopic in suprahyoid location with eutopic thyroid. Dual ectopia is very rare.(14)

Thyroid functional status was hypothyroid in $30-70 \%$ of the reported cases,(15) only few cases were hyperthyroid.(16) KEM study ${ }^{(9)}$ reported hypothyroidism in $67 \%$ of the cases and subclinical hypothyroidism in $17 \%$ of the cases. In Korean study,(5) $62 \%$ of the cases had hypothyroidism and 385 were euthyroid. In another case series by Somnath Saha et al,(11) all cases were hypothyroid. In our series hypothyroidism and subclinical hypothyroidism was found in $52.38 \%$ of the cases, $38 \%$ of the cases respectively, whereas euthyroid state was found in $9.52 \%$ of the cases. None of the cases were hyperthyroid in our series.

Management of the ET should be individualised, as there is no consensus on the optimum management. Factors influencing the management decisions are the location of the ET, size, functional status and compressive or obstructive symptoms. Levothyroxine therapy is recommended for patients with either subclinical hypothyroidism or frank hypothyroidism. Treatment with levothyroxine reduces the size of the gland. Some authors recommend levothyroxine therapy for euthyroid patients also.(17) Careful observation and follow-up may be a better approach for patients with asymptomatic ectopic thyroid, which are detected incidentally and functionally euthyroid. Surgery is indicated for patients with large ectopic causing upper airway obstruction, haemorrhage, infection or malignant degeneration. Postoperatively these patients require levothyroxine, because ectopic thyroid is the only functioning tissue. Autotransplantation of excised thyroid has been attempted.(18,19) Steinwald et al(20) reported $30 \%$ of patients remained euthyroid with autotransplantation, not requiring levothyroxine therapy. Radioactive ablation may be another approach for elderly patients with symptomatic ectopic, who refuse or not fit for surgery.(19) In our series $81 \%$ of the cases who were hypothyroid treated medically with levothyroxine, $9.52 \%$ of the euthyroid patients also received medical therapy, whereas $9.52 \%$ underwent surgery who had large ectopic with obstruction. In KEM series, $86 \%$ of the cases were treated medically and surgery was performed in $14 \%$ of the cases.

\section{CONCLUSION}

Ectopic thyroid gland is rare, but should be considered in the evaluation of midline neck swelling, especially in children with hypothyroidism. Clinical examination, thyroid profile and nuclear imaging aid in the diagnosis. Management should be individualised.

\section{REFERENCES}

1. Comajuan SM, Ayerbe JL, Ferrer BR, et al. An intracardiac ectopic thyroid mass. Eur J Echocardiogr 2009;10(5): 704-6.

2. Spinner RJ, Moor KL, Gottfried MR. Thoracic intrathymic thyroid. Ann Surg 1994;220(1):91-6.

3. Eyuboglu E, Kapan M, Ipek T, et al. Ectopic thyroid in the abdomen: report of a case. Surg Today 1999;29(5):472-4.

4. Hagiuda J, Kuroda I, Tsukamoto T. Ectopic thyroid in an adrenal mass: a case report. BMC Urol 2006;6:18.

5. Yoon JS, Won KC, Cho IH, et al. Clinical characteristics of ectopic thyroid in Korea. Thyroid 2007;17(11):1117-21.

6. Sauk JJ. Ectopic lingual thyroid. J Pathol 1970;102(4): 239-45.

7. Gillam MP, Kopp P. Genetic regulation of thyroid development. Curr Opin Pediatr 2001;13(4):358-63.

8. Felice DM, Lauro DR. Thyroid development and its disorders: genetic and molecular mechanisms. Endocrine Reviews 2004;25(5):722-46.

9. Gopal RA, Acharya SV, Bandgar T, et al. Clinical profile of ectopic thyroid in Asian Indians: a single-center experience. Endocrine Practice 2009;15(4):322-5.

10. Kaplan M, Kauli R, Lubin E, et al. Ectopic thyroid gland. A clinical study of 30 children \& review. J Pediatr 1978;92(2):205-9.

11. Saha S, Ghosh A, Pal S, et al. Ectopic thyroid tissue -a case series. Philippine Journal of Otolaryngology-Head And Neck Surgery 2013;28(1):10-4.

12. Noyek AM, Friedberg J. Thyroglossal duct and ectopic thyroid disorders. Otolaryngol Clin North Am 1981;14(1):187-201. 
13. Okstad S, Mair IW, Sundsfjord JA, et al. Ectopic thyroid tissue in the head and neck. J Otolaryngol 1986;15(1): 52-5.

14. Huang TS, Chen HY. Dual thyroid ectopia with a normally located pretracheal thyroid gland: case report and literature review. Head Neck 2007;29(9):885-8.

15. Danner C, Bodenner D, Breau R. Lingual thyroid: iodine 131: a viable treatment modality revisited. Am J Otolaryngol 2001;22(4):276-81.

16. Shah BC, Ravichand CS, Juluri S, et al. Ectopic thyroid cancer. Ann Thorac Cardiovasc Surg 2007;13(2):122-4.
17. Kansal P, Sakati N, Rifai A, et al. Lingual thyroid. Diagnosis and treatment. Arch Intern Med 1987;147(11):2046-48.

18. Hazarika P, Siddiqui SA, Pujary K, et al. Dual ectopic thyroid: a report of two cases. J Laryngol Otol 1998;112(4):393-5.

19. Kalan A, Tariq M. Lingual thyroid gland: clinical evaluation and comprehensive management. Ear Nose Throat J 1999;78(5):340-9.

20. Steinwald OP, Muehrcke RC, Economou SG. Surgical correction of complete lingual ectopia of the thyroid gland. Surg Clin North Am 1970;50(5):1177-86. 